\title{
Analysis of the linkage between China and US stock markets
}

\author{
Dayan Lin, Lei Qi ${ }^{*}$ \\ School of Economics and Management, Nanjing University of Science and Technology, \\ Nanjing 210094 \\ *Corresponding author: Lei Qi, Master, 1328424263@qq.com
}

\begin{abstract}
With the prosperity of China financial markets, the influence of China stock market is further enhanced. This paper analyses the linkage of China and US stock markets. The data consists weekly price index values for Shanghai Composite Index and the Nasdaq Index from 1991 to 2017. Results show that in all period US stock market has a single Granger causality with China market. China and US stock market have causal relationship with long-term stability after 2008 financial crisis, but there is one-way impact without long-term stability before the crisis. Finally, this paper explores that development of China capital market and economic power contributes to the results.
\end{abstract}

Key words: Stock markets; ADF; granger causality test; co-integration;

\section{Introduction}

With the opening of China capital market, its importance gradually appears. Since the 21st century, China stock market plays a role of barometer of the national economy. The market gets mature gradually, but it still belongs to the ranks of emerging markets compared to US stock market. Some scholars have found that major stock indexes in the international securities market are showing a similar trend (Jeonandvon Furstenberg, 1990). And the promotion of economic globalization has led to closer ties between different countries and regions. China and the US are now the world's top two economies, while two countries interact with each other significantly. China and the United States have established long-term friendly relations of cooperation, and bilateral trade continues to increase ${ }^{1}$. They constitute a strong economic complementarities. The linkage relationship between the securities market is no longer limited to the previous geographical location and economic and political similarities, such as Liu Jinquan (2002) found that Shanghai and Shenzhen stock markets exist cointegration relationship. Yu Shidian and Chen Shoudong (2001) studied Shanghai and Shenzhen stock markets and major stocks markets in the world ${ }^{2}$ (US, UK, Hong Kong and 
Japan). They found that China stock markets and the international major stock markets did not have co-integration relationship, that is to say there is no long-term common trend. However, foreign markets have single Granger causality for the domestic markets. On February 27, 2007, when Chinese stock market was in a state of collapse, US and other countries' stock markets were in a quagmire, and the relationship between China stock market and other stock markets was inseparable. China stock market plunged from June to September 2015 while other stock markets also fluctuated significantly. During these studies of changes between China stock market and the global stock markets, scholars found it is very necessary to continue the study. This paper chooses the United States as a representative of mature stock markets. Through the analysis of China and US stock markets, the author wants to find out how China stock market affect global markets and to measure the extent of mutual influence. In other words, we need to analyze the linkage between China and US securities markets.

\section{Data and methodology}

\subsection{Data selection and processing}

This paper chooses the stock index to research because the stock index itself is the forerunner of stock market. It leads the trend of the whole market. Using the average change method to describe the stock market dynamics is effective for the measurement of stock market volatility in all countries, as well as the mutual influence among stock markets.

Shanghai Stock Index (SSI) is the representative of China stock market and NASDAQ index represents US stock market. The data is consist of Stock index closing prices weekly from January 2, 1991 to July 6, 2017. We use weekly prices to minimize effects of cross-country differences in weekend market closures ${ }^{3}$. Because China and US stock market trading day is slightly different, this paper deletes some transaction data that two markets do not overlap. Finally we got data about 1269. In this paper, we use the residual variance to calculate the fluctuation of the two different stock markets, and then make the Granger causality test and co-integration test to find out the relationship between two markets. The weekly data for the Nasdaq index came from the FRED, and the weekly closing price of Shanghai Composite Index came from "Eastern Fortis" software with some data processing.

Since the absolute value of the stock index is too large, it is not convenient to deal with data. Therefore, this paper makes a logarithmic processing of the index data. The logarithmic function is a monotonically increasing function in its domain. After taking the logarithm, the relative size does not changed, and it has many advantages: it can reduce the absolute value of 
the data so that the calculation is more convenient; it shows high sensitivity about slight difference. This method of data processing is the most common in financial data study.

\subsection{Methodology}

The Granger causality test is a method proposed by Granger (1969) and promoted by Sims (1972) to determine whether a variable change will cause another variable to change. When we analyze the data of each economic variable, we often need to judge whether there is a certain causal relationship between two variables.

The co-integration test verifies the long-term relationship of variables and evaluates whether the long-term relationship changes. First we proposed null hypothesis that there is no cointegration. Use the trace test or the maximum eigenvalue test to determine whether to reject the original hypothesis. When $\mathrm{r}=\mathrm{n}$, if $\mathrm{p}$ value is less than $5 \%$, then reject the original hypothesis, that it means there are $n$ co-integration relationship. If p value is greater than $5 \%$, it means there is no co-integration relationship.

The stock index fluctuation is calculated by the variance of the residuals which come from regression model . The specific process is as follows:

$\mathrm{M}_{1 \mathrm{t}}$ and $\mathrm{M}_{2 \mathrm{t}}$ represent the stock index of the United States and China in $\mathrm{t}$ week.

Estimate the time trend of the index and we can write:

$$
\hat{M}_{1 t}=\hat{\alpha}_{1}+\hat{\beta}_{1 t}, \quad \hat{M}_{2 t}=\hat{\alpha}_{2}+\hat{\beta}_{2 t}
$$

$e_{1 t}$ and $e_{2 t}$ represent the deviation from its linear trend of $\mathrm{M}_{1 \mathrm{t}}$ and $\mathrm{M}_{2 \mathrm{t}}$.

$$
e_{1 t}=M_{1 t}-\hat{M}_{1 t}, \quad e_{2 t}=M_{2 t}-\hat{M}_{2 t}
$$

The volatility of US and China stock index are expressed as $\operatorname{Var}\left(e_{1 t}\right)$ and $\operatorname{Var}\left(e_{2 t}\right)$;

Cov (e1, e2) represents the relationship of deviation in two countries;

In this paper, the variance is used to measure the fluctuation of the market, and the correlation coefficient is used to measure mutual effect of fluctuation in two countries.

\section{Results and discussion}

\section{1 stock market volatility}

The volatility of the stock market affects the investment intention of the investors and then influences stock trend indirectly. It is the uncertainty of the stock market risk. In this paper, the variance of linear regression residual is used to measure the change. 
Observed from the actual markets, we can know that US stock index change is smaller than Shanghai Composite Index. However, there is still same trend in some stages. In one side, global economy developed in similar trend. On the other side, large economies interact so as to lead the big events spread around the world rapidly. For example, financial crisis in 2008 and stock market crash in 2015 amplify the change between two economies.

Table 1 - The Volatility of US and China stock markets

\begin{tabular}{|c|c|c|}
\hline $\operatorname{Var}\left(\mathrm{e}_{1 \mathrm{t}}\right)$ US & $\operatorname{Var}\left(\mathrm{e}_{2 \mathrm{t}}\right)$ China & $\operatorname{Cov}\left(\mathrm{e}_{1}, \mathrm{e}_{2}\right)$ \\
\hline 496989 & 452938 & 0.10 \\
\hline
\end{tabular}

Table 1 shows the results of the stock index volatility. Var（e1t）>Var（e2t）,it indicates that the overall volatility of US market is larger than China stock market. The uncertainty gives more chance to invest and it may due to the weak development of china stock market. The correlation coefficient of two series of volatility is 0.1 , and the correlation of two markets is 0.66. We can draw a conclusion that two markets do have a certain correlation and the volatility of US market is more obvious.

\subsection{Unit root test}

Unit root test refers to whether there is a unit root in the time sequence. If there is a unit root and it proves that the time series is not smooth, so it cannot carry out other test analysis directly. The presence of a unit root for a single variable sequence may make the time series unsuitable. So before the causality test and co-integration test, we need to make sure there is no false regression in time series. In this paper, the ADF statistic as unit root test is used to measure the smoothness of the data.

Table 2 - Unit root test of Two stock markets

\begin{tabular}{|c|c|c|c|}
\hline & & t-Statistic & Prob. $^{*}$ \\
\hline \multirow{2}{*}{ ADF test statistic } & logus & -2.121128 & 0.2364 \\
\cline { 2 - 4 } & D(logus) & -29.78646 & 0.0000 \\
\hline \multirow{2}{*}{ ADF test statistic } & $\log c$ & -3.169968 & 0.0220 \\
\cline { 2 - 4 } & D(logc & -32.20297 & 0.0000 \\
\hline
\end{tabular}

Table 2 shows that the logarithm sequence of US stock index accepts the original hypothesis. There is a unit root in original data but after further testing about the differential sequence, it is found that the original hypothesis of the unit root is significantly rejected, indicating that the differential sequence of US stock market is stationary. The logarithmic series of China stock market are stable at a significant level of $5 \%$, and the first difference is also stable. The logarithm and the first difference are both stable, and we will continue the following tests. 


\subsection{Granger causality test}

Granger causality test is to determine whether there is a causal relationship between two variables. Unit root test results shows US stock index logarithm sequence and China stock index logarithm sequence are integrated of order one.

Table 3 - Granger causality test

\begin{tabular}{|c|c|c|c|}
\hline Null Hypothesis & Obs & F-Statistic & Prob. \\
\hline 1.LOGUS does not Granger Cause LOGC & \multirow{2}{*}{1267} & 2.79614 & 0.0614 \\
\cline { 1 - 1 } 2.LOGC does not Granger Cause LOGUS & 1.71395 & 0.1806 \\
\hline
\end{tabular}

From Table 3, we can see that p value is 0.0614 , and original hypothesis1 is rejected at the significant level of $10 \%$ in the lagged period 2, which means that US stock index changes is the reason for the change of China stock index. For original hypothesis2, $\mathrm{p}$ value is greater than 0.1 so the test accepts. This shows that the causal relationship between US and China stock index is only single way. The change of US market can influence Chinese market, but the change of Chinese market has no significant effect on US stock market ${ }^{4}$.

With the further opening-up of China capital market, its capital strength is becoming more and more important in the world. Because of the impact of financial crisis in 2008, capital strength changed a lot under the competition and China capital market cannot be underestimated. So in this paper, time series is divided into two stages: before 2008 and after 2008. And $\log u s 1, \log u s 2, \log 1, \log 2$ represent different stages. We use data to do the same tests and to determine whether the relationship of US and China capital markets is different.

Table 4 - Unit Root Test Results of different stages

\begin{tabular}{|c|c|c|c|c|}
\hline & Logus1 & Logus2 & Logc1 & Logc2 \\
\hline $\log (\mathrm{p})$ & 0.2093 & 0.9072 & 0.2510 & $0.0255(5 \%)$ \\
\hline $\mathrm{D}(\mathrm{Log})(\mathrm{p})$ & 0.0000 & 0.0000 & 0.0000 & 0.0000 \\
\hline
\end{tabular}

It can be seen from Table 4 that all time series data are stable under the first order difference, which conforms to the same order and can be used for Granger causality test.

Table 5 - Grange causality test of different stages

\begin{tabular}{|c|c|c|c|r|}
\hline Null Hypothesis & & Obs & F-Statistic & \multicolumn{1}{|c|}{ Prob. } \\
\hline LOGUS1 does not Granger Cause LOGC1 & & & 3.27266 & 0.0708 \\
\hline LOGC1 does not Granger Cause LOGUS1 & \multirow{2}{*}{$1991-2007$} & 847 & 1.25180 & 0.2635 \\
\hline LOGUS2 does not Granger Cause LOGC2 & & & 0.65232 & 0.7334 \\
\hline LOGC2 does not Granger Cause LOGUS2 & \multirow{2}{*}{$2008-2017$} & 413 & 1.88905 & 0.0603 \\
\hline
\end{tabular}

It can be seen from Table 5 that under the condition of lagging period, US stock index from 1991 to 2007 is the Granger cause of the China stock index. The p value is 0.0708 and less 
than 0.1 , the original hypothesis is rejected at the $10 \%$ significance level. However, the impact of US stock market to China is no longer significant in 2008-2017.

During 1991to 2007, China stock index is not the cause of US stock index. After financial crisis in 2008, there may be some changes. When the stage is from 2008 to 2017, p value is 0.0603, which rejects the original level at 10\% Hypothesis. Before 2008, compared to the US, capital strength of China is very small, but now it's significantly enhanced.

\subsection{Co-integration test}

Granger causality test finds the relationship between two variables, but the choice of different lag may also lead to incompatible causal relationship structure, so we have to test long-term relationship. This paper uses the Johansen co-integration test to detect the long-term relationship between US stock index and China stock index.

Table 6 - Co-integration test results

\begin{tabular}{|c|c|c|c|c|}
\hline Hypothesized No. of CE(s) & Eigenvalue & Trace Statistic & 0.05 Critical Value & Prob.** \\
\hline None $^{*}$ & 0.014257 & 22.79355 & 18.39771 & 0.0114 \\
\hline At most $1 *$ & 0.003667 & 4.643537 & 3.841466 & 0.0312 \\
\hline
\end{tabular}

It can be seen from table6 that the original hypothesis is rejected at the significance level of $5 \%$, which means that there is a long-term co-integration relationship between US and China stock index. With the further development of economic strength, China capital market has a certain status, which proves the empirical results of this paper.

In order to test China's changes before and after the financial crisis, co-integration test also divided the data into two stages. We judge China Changes in capital strength.

Table 7 - Co-integration test results of two stages

\begin{tabular}{|c|c|c|c|c|c|}
\hline & Hypothesized No. of CE(s) & Eigenvalue & Trace Statistic & 5\% Critical Value & Prob.** \\
\hline \multirow{2}{*}{$1991-2007$} & None & 0.012216 & 13.70460 & 15.49471 & 0.0914 \\
\cline { 2 - 6 } & At most 1 & 0.003958 & 3.343180 & 3.841466 & 0.0675 \\
\hline \multirow{2}{*}{$2008-2017$} & None * & 0.041800 & 22.28525 & 18.39771 & 0.0136 \\
\cline { 2 - 6 } & At most 1 * & 0.011197 & 4.650528 & 3.841466 & 0.0310 \\
\hline
\end{tabular}

It can be seen from Table7 that there is no co-integration relationship between two countries during 1991 to 2007. From 2008 to 2017, p value is 0.031, the original hypothesis is rejected at the level of 5\%. There is co-integration relationship between China and US stock index. After the reform of China financial market and the process of internationalization of renminbi , China security market has improved, we survived from financial crisis and get strong 5 . 


\section{Conclusions}

The results of the Granger causality test show that US stock index is the cause of China stock index. Before financial crisis in 2008, US stock index is the cause of China market, but China stock index did not affect US market. The situation changed after crisis, and China market influences US market, the impact of reverse relationship is not significant. It is not surprising that because of stock market globalization and strong economy, so that exchange reserves and foreign trade grow quickly, then the relationship between two countries get closer.

China and US markets have a long-term co-integration relationship. In the period from 1991 to 2007 there is no long-term stable relationship, but in 2008-2016, there is a long-term common trend, with a stable relationship. China stock market is weak before the financial crisis, but it has a good performance in this crisis so investors are attracted by this emerging market with huge space for development. Chinese government continued to carry out financial reform while the linkage of China and US stock markets become more prominent.

Since 2008, China stock market has developed rapidly and has been successfully connected with international market. China economy accounts for great proportion of capital markets, attracting the attention of global investors and accelerating economic integration. The risks increased sharply. China should pay attention to the speed of capital liberalization and the fluctuation of international market risk in the financial market reform, and keep healthy and long-run development of financial market in the process of liberalization.

\section{References}

1. Bing Zhang, Zhizhen Fan, Xindan Li, Study on the linkage of the stock market in China and America, J. Economic Research 11 (2010) 141-151.

2. Shidian $\mathrm{Yu}$, Shoulong Chen, Lihua Huang, The main stock index linkage analysis, J. Statistical analysis 08 (2001) 42-46.

3. Francesco Guidi and Mehmet Ugur, Are South East Europe stock markets integrated with regional and global stock markets, MPRA Paper No. 44133, posted 2.2012 (10).

4. Wei Chen, Study on the Linkage of Sino-American Stock Market, J. Management Observation 23 (2008) 288-289.

5. Ying Gao, Lili Jin, Analysis of the Correlation between Shanghai and Shenzhen 300 Index and World Major Stock Index, J. Management Review. 2008.20. 